\title{
Socio-economic and demographic determinants of under-five mortality in rural northern Ghana
}

\author{
Edmund Wedam Kanmiki ${ }^{1 *}$, Ayaga A Bawah², Isaiah Agorinya' ${ }^{1}$, Fabian S Achana', John Koku Awoonor-williams ${ }^{3}$, \\ Abraham R Oduro ${ }^{1}$, James F Phillips ${ }^{2}$ and James Akazili ${ }^{1}$
}

\begin{abstract}
Background: In spite of global decline in under-five mortality, the goal of achieving MDG 4 still remains largely unattained in low and middle income countries as the year 2015 closes-in. To accelerate the pace of mortality decline, proven interventions with high impact need to be implemented to help achieve the goal of drastically reducing childhood mortality. This paper explores the association between socio-economic and demographic factors and under-five mortality in an impoverished region in rural northern Ghana.
\end{abstract}

Methods: We used survey data on 3975 women aged 15-49 who have ever given birth. First, chi-square test was used to test the association of social, economic and demographic characteristics of mothers with the experience of under-five death. Subsequently, we ran a logistic regression model to estimate the relative association of factors that influence childhood mortality after excluding variables that were not significant at the bivariate level.

Results: Factors that significantly predict under-five mortality included mothers' educational level, presence of co-wives, age and marital status. Mothers who have achieved primary or junior high school education were $45 \%$ less likely to experience under-five death than mothers with no formal education at all (OR $=0.55, p<0.001)$. Monogamous women were $22 \%$ less likely to experience under-five deaths than mothers in polygamous marriages $(\mathrm{OR}=0.78, \mathrm{p}=0.01)$. Similarly, mothers who were between the ages of 35 and 49 were about eleven times more likely to experience under-five deaths than those below the age of 20 years $(O R=11.44, p<0.001)$. Also, women who were married had a $27 \%$ less likelihood $(O R=0.73, p=0.01)$ of experiencing an under-five death than those who were single, divorced or widowed.

Conclusion: Taken independently, maternal education, age, marital status and presence of co-wives are associated with childhood mortality. The relationship of these indicators with women's autonomy, health seeking behavior, and other factors that affect child survival merit further investigation so that interventions could be designed to foster reductions in child mortality by considering the needs and welfare of women including the need for female education, autonomy and socioeconomic well-being.

Keywords: Under-five mortality, Socio-economic, Demographic, Determinants, Rural, Ghana

\section{Background}

Under-five mortality decline has improved from $1.2 \%$ per year between 1990 and 1995 , to $3.9 \%$ per year between 2005 and 2012 [1]. In spite of this substantial drop in global child mortality rate, about 6.6 million children still die every year before their fifth birthday worldwide which implies 18,000 under-five children die

\footnotetext{
* Correspondence: eddy100@hotmail.com

${ }^{1}$ Navrongo Health Research Centre, Ghana Health Service, Upper East Region, Box 114, Navrongo, Ghana

Full list of author information is available at the end of the article
}

each day [1]. There are huge disparities in child mortality among low and middle income countries and the industrial world with Sub-Saharan Africa and South East Asia carrying the highest burden of under-five mortality [2-4].

Children in sub-Saharan Africa have the highest risk of death in the first month of life and are still leading in under-five mortality rates with one in every nine children dying before their fifth birthday as of 2011 [2].

It is worth noting that the year 2008 recorded a rate of one in seven children (144 per 1000 live births) dying 
before their fifth birthday with the highest levels occurring in West and Central Africa. Within 34 countries where under-five mortality exceeded 100 out of 1000 live births in 2008, all except one are in sub-Saharan Africa [5]. The rate of improvement in child survival in SubSaharan Africa is insufficient to meeting United Nations Millennium Development Goal 4 of reducing under-five mortality rate by two-thirds between 1990 and 2015 as it has the highest risk of death in the first month of life and is among the regions showing the least progress globally $[1,2]$.

In order to accelerate the decline in under-five mortality rate, specific proven interventions would have to target important causes of child death [6-8]. Since no single factor can account for the high child mortality [9], in developing these interventions there is the need to understand the multiplicity of factors that determine child mortality especially in resource poor settings $[10,11]$.

Previous studies have shown that various factors influence child health and survival including place of residence, mothers age, mother's education, place of delivery, birth order, sex of child, religion of parents, household headship and household socio economic status [9,12-18].

Though poverty is well acclaimed as an essential factor influencing child mortality $[4,14,19,20]$, findings on the effect of household socio economic differentials on child mortality have been mixed. A study in parts of rural Ghana and another in Tanzania did not find any significant effect of household socio economic status on child mortality $[18,19]$ while a study using Nigeria Demographic and Health Survey for 2008, found that relatively prosperous households were less likely to experience child death than the poorest households in rural Nigeria [13].

Existing literature has documented mixed results, such as place of delivery, birth order and sex of child. For instance, abundance of evidence suggest that women who deliver at health facilities have a lower chance of child death as compared to those who deliver at home due to the use of skilled delivery at health facilities and the none existence of such at home [6,12-14]. However, studies in South Africa and parts of Nigeria suggest that place of delivery does not have significant effect on either perinatal or under-five mortality $[16,17]$.

In Ghana, just as in many other countries in SubSaharan Africa with low socio economic development, under-five mortality is relatively high with a recent reported national figure of 90 per 1000 live births [21]. Moreover within Ghana, disparities exist in under-five mortality rates between regions. In the more resource rich regions of southern Ghana, under-five mortality rate ranges from 75 per 1000 live births whiles in the most impoverish and deprived regions of the north such as the Upper East Region it is as high as 128 per 1000 live births [21]. Therefore there is the need for concerted efforts especially in resource poor settings if we hope to achieve the desired improvements in under-five mortality.

Due to disagreements in existing literature on the influence of particular social, economic and demographic attributes of mothers on under-five mortality coupled with sparse information on the topic in the Ghanaian setting, this paper further examine social, economic and demographic factors that influence under-five deaths and the magnitude of their influence in a rural impoverished setting in northern Ghana. It is hoped that findings from this paper will contribute to literature on under-five mortality in rural poor settings and perhaps contribute to identifying priority interventions to address the persistent mortality in settings such as this.

\section{Methods}

Study setting

The study was carried out in the Upper East Region of Ghana. Located in the northernmost part of Ghana, the region has a population of about 1,046,545 with an annual growth rate of $1.2 \%$ [21]. The region is predominantly rural, with $79 \%$ of its residents located in rural areas and as high as $72.3 \%$ of households are headed by males, total fertility rate is 3.43 and under-five mortality stands at 128 per 1000 live births [21]. The region is made up of about seven ethnic groups all of which are patriarchal in nature. Social research has documented customs of gender stratification that constrain female autonomy with respect to decision making, household governance and health seeking behavior [22]. Subsistence agriculture constitutes the mainstay of the economy of this region contributing as high as $83.7 \%$ of households' economic activity $[21,22]$. The area is characterized by two main seasons, a short rainy season from May to September and a long dry season from October to April. With such pervasive dependence on subsistence rain-fed agriculture, the region ranks among Ghana's most impoverished regions [19,22,23], with low literacy and a per capita income level that is estimated to be about a quarter of the level estimated for Ghana as a whole [24].

\section{Study design}

This paper makes use of data from a cross-sectional baseline survey of the Ghana Essential Health Intervention Project (GEHIP) conducted in 2011. The purpose of this survey was to provide the project team with detailed information on maternal and child health, fertility, family planning, universal health coverage and other basic health indicators for eventual evaluation of the project.

GEHIP is a five year health systems strengthening and research program being conducted in the Upper East 
region of Ghana. It seeks to improve Ghana's comprehensive primary healthcare initiative, known as the Community-based Health Planning and Services Program (CHPS). CHPS provides a wide range of essential preventive and curative services to some of Ghana's most rural and impoverished locations but has however been faced with serious service gaps and operational flaws preventing it from achieving its full potential [20]. The GEHIP strategy includes introducing a series of training and technical assistance programs aimed at strengthening the capacity of the health systems. Also, additional maternal and child health interventions are being added and increased support provided to system structures to enhance overall effectiveness [20]. GEHIP is being implemented by the Upper East Regional Health Directorate of the Ghana Health Service (GHS) with technical assistance from the Mailman School of Public Health, Columbia University and the school of Public Health of the University of Ghana. Navrongo Health Research Center (NHRC) has the responsibility to provide data for the evaluation of GEHIP.

With the exception of the Kassena-Nankana East and West Districts which are research sites of the Navrongo Health Research Centre (NHRC), the other seven districts in the region as of 2011 were involved in the survey. The districts include: Bawku East Municipality, Bawku West, Talensi-Nabdam, Garu-Tempane, Bongo, Builsa and Bolgatanga Municipality. The sampling unit of the survey was the household, which is defined as 'a person or group of persons living together in the same house or compound, sharing the same housekeeping arrangements and being catered for as one unit' [25]. The sample frame was obtained from the Ghana Statistical Service (GSS). A two-stage sampling procedure was involved, the GSS sampled 66 enumeration areas (EAs) and Probability sampling proportional to population size was used, all women age 15-49 years in sampled households were eligible to be interviewed using a structured questionnaire. A total of about 5400 women were interviewed, however, this paper is based on 3,975 of the women representing those who have ever given birth.

\section{Socio-economic and demographic variables}

The variables used in this study included mother's age, mothers' highest level of education, rural/urban residence, mother's marital status, occupation, religion, autonomy, mother's involvement in polygamous marriage, contraceptive use, national health insurance registration status and household socio economic status.

\section{Data analysis}

STATA 11.2 was used for all the analysis. For the purpose of this paper, the unit of analysis is respondents who had experienced child birth and the measurable outcome was the experience of under-five death. Mothers' age was recoded into three categories (15-19, 20-34 and 35-49). Mother's highest level of education was also categories into three: those whose highest level of education was primary or junior high school were merged into one category while senior high school and tertiary were also merged into another. Respondents' marital status was recoded: all who had reported to be single, widowed, divorced or separated were merged and labeled as 'not married'. Place of residence was also recorded as either urban or rural. Occupation was recoded into five categories: all respondents who were involved in trading, craftsmanship, dressmaking etc. were merged and classified as "self-employed". The other categories under occupation are: farming, government employed, student and others.

In determining the variable autonomy, a question was posed to respondents as to who often makes decisions about major household purchases and this was recorded, respondents who answered that they personally made those decisions themselves and those who answered that they do that jointly with their husbands were merged together and considered to be autonomous while respondents who said that it was the sole prerogative of their husbands and those who answered that someone else other than they or their husbands, were merged and considered 'not autonomous'.

We used principal component analysis (PCA) a multivariate approach to compute wealth index by using household assets as a proxy to estimate household socioeconomic status. In all 13 household items (assets) were involved in the analysis and wealth index was classified into 3 socio-economic tertiles namely: relatively poor, middle and rich.

Bivariate analysis using chi square test was used to test for association between the independent outcome variables and ever experiencing under-five death. All variables that showed significant association $(\mathrm{p}<0.05)$ in the bivariate analysis were then included in the multivariate analysis (logistic regression model). We calculated odds ratios with each covariate. Variables used in the logistic regression were first tested for multi co-linearity using the variance inflation factor (VIF) and this was found not to be a problem with an average VIF of 2.54 (VIF more than 20 indicates multi co-linearity). In calculating the odds ratio for each category of the independent variables, the first group was always taken as the reference category.

\section{Ethical consideration}

Before the baseline was conducted for GEHIP, ethical clearance was sought from ethics committees of the Ghana Health Service and the Navrongo Health Research Centre Institutional Review Board (NHRC IRB). 
Inform Consent was obtained from each participant. Also data sets used were anonymous of participant identity.

\section{Results}

\section{Characteristics of study participants}

In all 3,975 respondents had ever experienced child birth. Of this number 1,481 representing 37.3\% had ever experienced under-five child death. 3.7\% were between 15-19 years, about half (50.9\%) were between 20-34 years whiles $45.4 \%$ were between $35-49$ years.

Only $3.1 \%$ of respondents had attained education up to senior high school or above while $75.6 \%$ had no formal education at all. About $12.9 \%$ where either not married, widowed, divorced or separated while $87.1 \%$ of respondents were observed to either be married or live with a man as if married. As high as $87.5 \%$ were observed to be rural dwellers, while $12.5 \%$ were resident in urban settings. With regards to religious affiliation, $51.8 \%$ belong to Christianity while $27.1 \%$ and $16.9 \%$ belong to Islamic and traditional religions respectively. In terms of occupation, $46.3 \%$ of respondents were engaged in farming, $36.5 \%$ were self-employed while only $12.1 \%$ were civil servants and less than $2 \%$ were students.

As high as $64.1 \%$ could be described as being "autonomous" that is: they make their own decisions about major household purchases or jointly with their husbands while $35.9 \%$ of respondents rely solely on their husbands or another relative to make such decisions. Also $34.1 \%$ of respondents were found to be in polygamous unions; that is their husbands have more than one partner. $58.8 \%$ of respondents were registered under the Ghana national health insurance scheme.

According to our wealth index on socio economic status using common household assets in rural northern Ghana, $43.8 \%$ were relatively poor, $20.8 \%$ were within the middle class while $35.4 \%$ were within the rich tertile. In terms of contraceptive use, $15.2 \%$ of respondents reported to be using contraceptives to delay or avoid getting pregnant. Table 1 below gives a detailed description of the background characteristics of the 3,975 respondents involved in this study.

\section{Bivariate analyses}

The results of the bivariate analysis of ever experiencing an under- five death and predictor variables are shown in Table 2 below. Respondents aged 35 years and above were more likely to experience under-five death compared to younger respondents $(\mathrm{p}<0.001,95 \% \mathrm{CI})$. Similarly, deaths among under-five children differed significantly with the level of respondents' education, with those of relatively higher education having a lower chance of experiencing under-five death $(\mathrm{p}<0.001)$. Marital status was also slightly associated with under-five death in bivariate analysis with respondents not married having a high chance of experiencing under-five death compared to those married ( $\mathrm{p}=0.04,95 \% \mathrm{CI})$.

Occupation of respondent was equally associated with experience of under-five deaths with higher proportions of those involved in farming and the self-employed experiencing under-five death compared to civil servants and students $(\mathrm{p}<0.001,95 \% \mathrm{CI})$. Religion of respondent was significantly associated with under-five death with those who practice no religion and those who practice traditional religion having higher chances of experiencing under-five death compared to those who practice Christianity and Islamic religions $(\mathrm{p}<0.001,95 \% \mathrm{CI})$. Place of residence was however slightly associated $(\mathrm{p}=$ $0.022,95 \% \mathrm{CI}$ ) with rural dwellers having slightly higher proportions of under-five death experience compared to that of urban dwellers.

The association of autonomy and childhood mortality was significant with respondents regarded as autonomous rather having a higher chance of experiencing an under-five death than those considered not autonomous $(\mathrm{p}<0.001,95 \% \mathrm{CI})$.

Also, polygamous status of respondents, contraceptive use, national health insurance coverage and socio economic status of respondent's household were all significant in the bivariate analysis $(\mathrm{p}<0.001,95 \% \mathrm{CI})$, those involved in polygamous unions had higher chance of experiencing under-five death than their counterparts, contraceptive users had a lower chance of experiencing under-five death compared to non-users while those covered under the national health insurance scheme were less likely to experience under-five death. The proportion of respondents in the rich tertile that experienced under-five death was slightly less than that of the middle class and the relatively poor tertiles.

\section{Multivariate analysis}

Table 3 below shows the results of the multivariate analysis (logistic regression model) of determinates of under-five mortality in rural northern Ghana.

In the model, respondent's age, highest level of education, marital status and polygamous status of partner were significant predictors of under-five mortality. Level of education had a statistically significant effect on experience of under-five death. For example women who had up to primary or junior high school education where $45 \%$ less likely (odds ratio $=0.55$ ) to experience an under-five death than those who had not attained any form of formal education at all and those who had up to senior high school or tertiary education where even $76 \%$ less likely (odds ratio $=0.24$ ) to experience under-five death than women without any formal education at all. Similarly age of respondent had a positive and statistically significant impact. Women who were between the ages of 35 and 49 years were about 11 times more likely 
Table 1 Background characteristics of respondents, 2011 [ $\mathrm{N}=3975$ ]

Background characteristics

Age group

Highest Level of education
Number (N)

145

2024

1806

3005

846

124

511

3464

Married

Farming

Self Employed

Government Employed

Student

Other

No response

Religion

1842
Christianity

Traditional

Islam

No response

Urban

Rural

Bawku East

Bawku West

Bolga M.

Bongo

Builsa

Garu/Tempani

Talensi/Nabdam

Autonomous

Not autonomous

2547

1428

1355

2139

481

No response

Not registered

2338

1637

2057

497
Percent (\%)

3.7

50.9

45.4

75.6

21.3

3.1

12.9

87.1

46.3

36.5

12.1

1.7

3.3

0.1

51.8

16.9

27.1

4.3

12.5

87.5

17.7

10.9

8.9

12.3

17.4

20.4

12.5

64.1

35.9

34.1

53.8

12.1

NHIS Coverage 
Table 1 Background characteristics of respondents, 2011 [N = 3975] (Continued)

Socio economic status (Wealth Index)

$\begin{array}{lll}\text { Poor } & 1742 & 43.8 \\ \text { Middle } & 828 & 20.8 \\ \text { Rich } & 1405 & 35.4\end{array}$

Contraceptive use

$\begin{array}{lll}\text { Yes } & 605 & 15.2 \\ \text { No } & 2459 & 61.9 \\ \text { No response } & 911 & 22.9\end{array}$

to experience under-five death than those below the age of 20 years. On the other hand, women who were married had a $27 \%$ less likelihood (odds ratio $=0.73$ ) of experiencing an under-five death than those who were either reported single, divorced or widowed.

Conversely, maternal occupation, religious affiliation and place of residence were not significant determinants of under-five mortality in the multivariate analysis. Autonomy, household socio economic status, enrollment in the national health insurance scheme and contraceptive use also did not confer significant odds of under-five mortality.

Being in a polygamous union however is significantly associated with under-five mortality, with children of mothers not in polygamous unions having significantly higher likelihood $(22 \%)$ of survival (odds ratio $=0.78$ ) than their counterparts.

\section{Discussion}

In this study we have examined the influence of particular social, economic and demographic characteristics of mothers on under-five mortality in rural northern Ghana. Results showed that several factors are implicated in under-five mortality.

The bivariate analysis shows that variables such as mother's age, level of education, marital status, place of residence, occupation, religion, autonomy, contraceptive use, national health insurance enrollment status, polygamous union and socio economic status were significantly associated with experience of under-five death in this largely rural setting. Controlling for the confounding effects of the various factors, mother's age, level of education, marital status and polygamy, were found to have significant robust association with childhood mortality.

Both multivariate and bivariate analysis indicate that children born to older mothers (35 years and above) were more at risk of under-five death compared to younger mothers (20 years of age), this is consistent with available literature that points to the fact that maternal age is a strong predictor of child survival [12,14,18]. Reasons for the childhood mortality disadvantage for older mothers may be twofold: first, older cohort mothers are less likely to be educated and therefore, less likely to be associated with the enhanced mortality advantage associated with education, and second, older mothers are more likely to be associated with higher parity.

Level of mothers' education emerged as a strong predictor of under-five mortality in both bivariate and multivariate analysis after controlling for other variables; this has long been acknowledged by other scholars $[4,9,14,16]$ though a few studies suggest otherwise [12]. The effect of maternal education on child survival is over whelming and cannot be over emphasized. The reasons may be that educated mothers are more likely to receive antenatal care and are more capable of gaining access to health care. Also education can contribute to child survival by delaying marriage and motherhood hence decreasing the total number of children a woman has [12]. Warren's findings from Ethiopia indicate that some women do not seek care due to lack of understanding of the benefits which has effects on child and maternal survival [26].

As presented in these findings, married women were less likely to experience child death than their unmarried counterparts and this was statistically significant even in the multivariate analysis. Not many studies have been done on the effect of mother's marital status on child mortality but one can sense that mothers in stable marriages would get support from their partners during antenatal through to postnatal care which can reduce risk of child mortality as shown by our results. Also, marriage may confer advantages such as pooling of resources to either patronize good health services or provide adequate care with respect to providing good nutrition to infants and children.

Religious affiliation did not show significant odds in the multivariate analysis though the odds points to the fact that respondents who did not practice any religion and those who practice traditional religion had a higher chance of experiencing under-five death than Christians and Muslims. This is consistent with a study in parts of Nigeria which showed that children born to mothers who practice traditional religion had increased risk of about thrice than the general population to experience perinatal deaths [17]. 
Table 2 Bivariate analysis of mother's experience of child death [N = 3975]

\begin{tabular}{|c|c|c|c|}
\hline \multirow{3}{*}{ Determinants } & \multicolumn{3}{|c|}{ Ever experiencing an under-five death $(n=3975)$} \\
\hline & YES & No & p-value \\
\hline & n (\%) & n (\%) & \\
\hline \multicolumn{4}{|l|}{ Age group } \\
\hline $15-19$ & 10(6.90) & 135(93.10) & \multirow{3}{*}{$<0.001$} \\
\hline 20-34 & $453(22.38)$ & $1571(77.62)$ & \\
\hline $35-49$ & $1018(56.37)$ & $788(43.63)$ & \\
\hline \multicolumn{4}{|l|}{ Highest level of education } \\
\hline None & $1282(42.66)$ & 1723(57.34) & \multirow{3}{*}{$<0.001$} \\
\hline Primary/Junior High School & 185(21.87) & $661(78.13)$ & \\
\hline Secondary/Tertiary & 14(11.29) & 110(88.71) & \\
\hline \multicolumn{4}{|l|}{ Marital status } \\
\hline Not married & $211(41.29)$ & $300(58.71)$ & \multirow[t]{2}{*}{0.043} \\
\hline Married & 1270(36.66) & 2194(63.34) & \\
\hline \multicolumn{4}{|l|}{ Occupation } \\
\hline Farming & $753(40.88)$ & 1089(59.12) & \multirow{5}{*}{$<0.001$} \\
\hline Self Employed & $520(35.86)$ & $930(64.14)$ & \\
\hline Government employed & 158(32.85) & $323(67.15)$ & \\
\hline Student & $5(7.35)$ & $63(92.65)$ & \\
\hline Other & $45(34.62)$ & $85(65.38)$ & \\
\hline \multicolumn{4}{|l|}{ Religion } \\
\hline Christianity & $702(34.13)$ & $1355(65.87)$ & \multirow{4}{*}{$<0.001$} \\
\hline Traditional religion & $302(45.07)$ & $368(54.93)$ & \\
\hline Islam & $402(37.29)$ & $676(62.71)$ & \\
\hline No response & $75(44.12)$ & $95(55.88)$ & \\
\hline \multicolumn{4}{|l|}{ Place of residence } \\
\hline Urban & $162(32.60)$ & $335(67.40)$ & \multirow[t]{2}{*}{0.022} \\
\hline Rural & 1319(37.92) & 2159(62.08) & \\
\hline \multicolumn{4}{|l|}{ Financial autonomy } \\
\hline Autonomous & $1020(40.05)$ & 1527(59.95) & \multirow[t]{2}{*}{$<0.001$} \\
\hline Not autonomous & $461(32.28)$ & $967(67.72)$ & \\
\hline \multicolumn{4}{|l|}{ Polygamous partner } \\
\hline yes & $609(44.94)$ & $746(55.06)$ & \multirow[t]{3}{*}{$<0.001$} \\
\hline No & $666(31.14)$ & 1473(68.86) & \\
\hline No response & $206(42.83)$ & $275(57.17)$ & \\
\hline \multicolumn{4}{|l|}{ NHIS registration } \\
\hline Not registered & $951(40.68)$ & 1387(59.32) & \multirow[t]{2}{*}{$<0.001$} \\
\hline Registered & $530(32.38)$ & $1107(67.62)$ & \\
\hline \multicolumn{4}{|c|}{ Socio economic status (Wealth index) } \\
\hline Poor & 687(39.44) & 1055(60.56) & \multirow{3}{*}{0.001} \\
\hline Middle & $325(39.25$ & $503(60.75)$ & \\
\hline Rich & $469(33.38)$ & $936(66.62)$ & \\
\hline \multicolumn{4}{|l|}{ Contraceptive use } \\
\hline Yes & 215(35.54) & $390(64.46)$ & \\
\hline No & 1003(40.79) & $1456(59.21)$ & $<0.001$ \\
\hline
\end{tabular}


Table 3 Respondents experience of under-five death

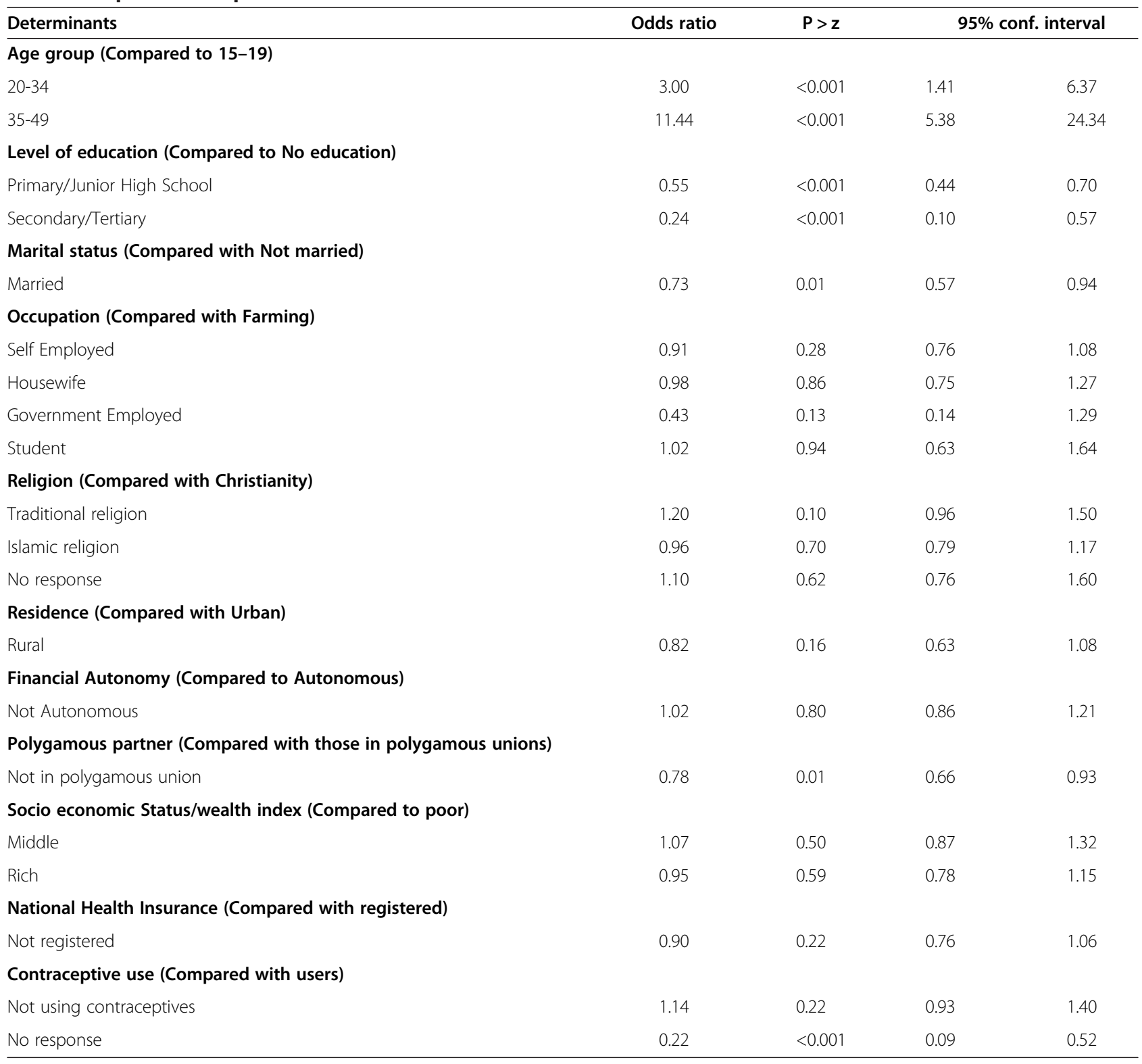

Logistic regression model.

Contrary to Ettarh and Kimani's findings in Kenya and another study in Nigeria which showed that rural poor mothers have a higher likelihood of experiencing child death than their urban counterparts [12,17], the findings of this study did not show any significant effect of place of residence on ever experiencing under-five death. It is likely the place of residence for some respondents could have changed between the time they experienced under-five death and the time of this survey. The existence of wide spread community based health planning and services program (CHPS) in the region could also partly be the reason for which place of residence did not confer significant odds on the experience of underfive deaths.
In spite of previous studies establishing that maternal autonomy promotes health-seeking behavior for sick children with positive outcomes on child survival $[9,13,27]$, this study did not seem to convincingly show the result of this on child survival. In this study we expected that mothers who profess to be financially autonomous would have significantly less chance of losing an under-five child but this is not so, as financially autonomous women were only $2 \%$ less likely to experience under-five death and this was not even statistically significant at the multivariate level. This may be due to our measure of autonomy. While other studies look at autonomy largely from education and employment [27] others perceive autonomy on the basis of decision 
making and to a large extend household headship. There is hence the need for a more concise and acceptable measure of female autonomy.

Another area which most studies have not looked at is the effect of polygamy on child mortality. This study shows that children whose mothers are in polygamous unions have $22 \%$ higher chance of experiencing underfive death than those in monogamous marriages. This may be due to possible rivalry from co-wives and neglect from husbands during pregnancy and early child care which is typical of African polygamous marriages with consequential effects on child survival. It could also be due to the fact that in this predominantly agrarian communities where women do not work and often tend to rely on the little resources that are provided by their husbands, women who are in polygamous marriages will be doubly stretched with regards to resources because the little the husband has will have to be shared among the several wives.

The effect of contraceptive use on under-five mortality though not significant at the multivariate level, it points to a $14 \%$ less likelihood of contraceptive users experiencing under-five death and a significant association in bivariate analysis. This is in line with other studies which have previously indicated a positive association of contraceptive use to low child death [9]. Therefore family planning methods are well recommended as an effective tool for birth spacing, prevention of unwanted pregnancies and affording mothers adequate time to care for the newborn and regain strength before conceiving again.

Contrary to most previous studies that had highlighted the effect of socio economic factors on child mortality $[4,9,12,13,15]$, socio economic status did not confer significant odds in the multivariate analysis. Owais et al. in examining why families of newborns do not accept hospital care in Pakistan identified largely financial reasons as a major barrier to access and utilization of health facilities [28]. Other studies have also indicated the role of socio economic differentials in health care seeking behavior with those of higher socio economic status more likely to use health care facilities than those at lower levels [28-30]. Which would invariably have a positive impact on child survival, but this is not what we observed here. Some studies suggest that the presence of wide spread community-based health planning and services program (CHPS) in the region has the potential to reduce the effect of socio economic differential on child mortality [19,23]. Studies in Vietnam and Nigeria showed that mothers from poor settings with transportation difficulty have a higher likelihood of child death [14,17]. Therefore in spite of these findings, we recommend interventions that improve the economic wellbeing of women in this setting given the prevalence of poverty in the area.

\section{Conclusion}

The causes of high under-five mortality in resource poor settings are complex and merit concerted efforts to clarify their implications to improve child survival. On the basis of these findings, we suggest that specific efforts with focus on under-five mortality decline need to target the individual needs and welfare of women. In order of priority, the promotion of female education, gender equity, family planning and addressing the vast socioeconomic differentials in northern Ghana are important social steps to improving under-five survival.

\section{Competing interests}

There is no competing interest.

\section{Authors' contribution}

EWK and JA conceived the study and participated in design and coordination of the study. EWK, JA, AB and FSA carried out the experiment. $E W K, J A$ and $I A$ did the data analysis. EWK, JA and $A B$ drafted the manuscript. JFP, AO, AB, JKA critically reviewed the paper. All authors read and approved of the final manuscript.

\section{Acknowledgements}

We are grateful to the African Health Initiative of the Doris Duke Charitable Foundation (DDCF) for funding the GEHIP project. We also acknowledge the invaluable assistance of staff of NHRC and the survey staff in particular for their hard work and dedication hence making the data collection a success. Lastly our profound gratitude goes to reviewers of this paper for critically reviewing the initial manuscript to produce this apt final piece.

\section{Author details}

Navrongo Health Research Centre, Ghana Health Service, Upper East Region, Box 114, Navrongo, Ghana. ${ }^{2}$ Department of Population and Family Health, Mailman School of Public Health, Columbia University, Columbia, USA. ${ }^{3}$ Upper East Regional Health Directorate, Ghana Health Service, Bolgatanga, Ghana.

Received: 20 May 2014 Accepted: 13 August 2014

Published: 21 August 2014

\section{References}

1. UNICEF, WHO, World Bank, UN-DESA Population Division: Levels and trends in child mortality; 2013. http://www.who.int/maternal_child_adolescent/documents/ levels_trends_child_mortality_2013.pdf?ua=1. (Access on 24 July 2014).

2. You D, New JR, Wardlaw T: Report on Levels and trends in child mortality, the United Nations Inter-agency Group for Child Mortality Estimation. 2014. (online) http://www.scribd.com/doc/128742911/Levels-and-Trends-in-Child-Mortality.

3. World Health Organization: Neonatal and Perinatal Mortality: Country, Regional, and Global Estimates. 2006. (Access on 25 January 2014) http://whqlibdoc.who.int/publications/2006/9241563206_eng.pdf.

4. Rahman S, Salameh K, Bener A, El Ansari W: Socioeconomic associations of improved maternal, neonatal, and perinatal survival in Qatar. Int J Womens Health 2010, 2:311-318. 32

5. You D, Wardlaw T, Salama P, Jones G: Levels and trends in under-5 mortality, 1990-2008. Lancet 2010, 375:100-103.

6. Jones G, Steketee RW, Black RE, Bhutta ZA, Morris SS: The Bellagio Child Survival Study Group. How many child deaths can we prevent this year? Lancet 2003, 362:65-71. (online) www.thelancet.com/pdfs/journals/lancet/ PIIS0140673603138111.pdf.

7. Darmstadt GL, Bhutta ZA, Cousens S, Adam T, Walker N, de Bernis L, the Lancet Neonatal Survival Steering Team: Evidence-based, cost-effective interventions: how many newborn babies can we save? Lancet 2005 , 365:977-988.

8. Bhutta ZA, Ahmed T, Black RE, Cousens S, Dewey K, Giugliani E, Haider BA Kirkwood B, Morris SS, Sachdev HP, Shekar M, Maternal and Child Undernutrition Study Group: What works? Interventions for maternal and child under nutrition and survival. Lancet 2008, 371:417-440. 
9. Adhikari R, Podhisita C: Household headship and child death; Evidence from Nepal. BMC Complement Altern Med 2010, 10:13.

10. Engmann C, Adongo P, Akawire Aborigo R, Gupta M, Logonia G, Affah G, Waiswa P, Hodgson A, Moyer CA: Infant illness spanning the antenatal to early neonatal continuum in rural northern Ghana: local perceptions, beliefs and practices. J Perinatol 2013, 33(6):476-481.

11. Black RE, Morris SS, Bryce J: Where and why are 10 million children dying every year? Lancet 2003, 361:2226-2234.

12. Ettarh RR, Kimani J: Determinants of under-five mortality in rural and urban Kenya. Rural Remote Health, 12:1812. (Online) 2012 access on 16 January 2014 at http://www.rrh.org.au.

13. Doctor HV: Does living in female-headed household lower child mortality? The case of rural Nigeria. Rural Remote Health, 11:1635. Online) 2011. Available: www.rrh.org.au (Accessed on 23 January 2014.

14. Swenson IE, Nguyen MT, Pham BS, Vu QN, Vu DM: Factors influencing infant mortality in Vietnam. J Biosoc Sci 1993, 25(3):285-302.

15. Teka T, Faruque ASG, Fuchs GJ: Risk factors for deaths in under-age-five children attending a diarrhea treatment Centre. Acta Paediatr 1996, 85:1070-1075.

16. Worku Z: Factors that affect under-five mortality among South African children: analysis of the South African Demographic and Health Survey Data Set. Proceedings of the World Congress on Engineering and Computer Science 2009, 2:1-3.

17. Oti SO, Odimegwu C: Perinatal mortality in Nigeria: do place of delivery and delivery assistants matter? Open Demography Journal 2011, 4:1-10.

18. Mturi AJ, Curtis SL: The determinants of infant and child mortality in Tanzania. Health Policy Planning 1995, 10(4):384-394.

19. Welaga P, Moyer CA, Aborigo R, Adongo P, Williams J, Hodgson A, Odoru A, Engmann C: Why are babies dying in the first month after birth? A 7-year study of neonatal mortality in northern Ghana. PLoS One 2013, 8(3):e58924. doi:10.1371/journal.pone.0058924.

20. Awoonor-Williams JK, Bawah AA, Nyonator FK, Asuru R, Oduro A, Ofosu A, Phillips JF: The Ghana essential health interventions program: a plausibility trial of the impact of health systems strengthening on maternal \& child survival. BMC Health Serv Res 2013, 13(Suppl 2):S3.

21. Ghana Statistical Service: 2010 Population and Housing Census, National Analytical Report. ; 2013. (Access on $25^{\text {th }}$ February 2014) http://www. statsghana.gov.gh/docfiles/2010phc/National_Analytical_Report.pdf.

22. Akazili J, Doctor HV, Abokyi L, Hodgson A, Phillips JF: Is there any relationship between antenatal care and place of delivery? Findings from rural northern Ghana. African Journal of Health Sciences 2011, 18:1-2.

23. Phillips JF, Bawah AA, Binka FN: Accelerating reproductive and child health programme impact with community-based services: the Navrongo experiment in Ghana. Bull World Health Organ 2006, 84(12):949-955.

24. Al-Hassan RM, Diao X: Regional Disparities in Ghana: Policy Options and Public Investment Implications, Background Paper No. GSSP 0002 Washington DC: International Food Policy Research Institute, Ghana Strategy Support Program (GSSP); 2006

25. Ghana Statistical Service and Macro International Inc: Ghana Demographic and Health Survey 1998. Accra, Ghana: Ghana Statistical service; 1999.

26. Warren C: Care of the newborn: Community perceptions and health seeking behavior. Ethiop J Health Dev 2010, 24:110-114.

27. Owais A, Sultana S, Stein AD, Bashir NH, Awaldad R, Zaidi AK: Why do families of sick newborns accept hospital care? A community-based cohort study in Karachi, Pakistan. J Perinatol 2011, 31:586-592.

28. Amin R, Shah NM, Becker S: Socioeconomic factors differentiating maternal and child health-seeking behavior in rural Bangladesh: a cross-sectional analysis. Int J Equity Health 2010, 9:9.

29. Chomat AM, Grundy J, Oum S, Bermudez Ol: Determinants of utilisation of intrapartum obstetric care services in Cambodia, and gaps in coverage. Global Public Health 2011, 6:8. 890-905.

30. Matsuoka S, Aiga H, Rasmey LC, Rathavy T, Okitsu A: Perceived barriers to utilization of maternal health services in rural Cambodia. Health Policy 2010, 95(2 3):255-263.

doi:10.1186/1472-698X-14-24

Cite this article as: Kanmiki et al: Socio-economic and demographic determinants of under-five mortality in rural northern Ghana. BMC International Health and Human Rights 2014 14:24.

\section{Submit your next manuscript to BioMed Central and take full advantage of:}

- Convenient online submission

- Thorough peer review

- No space constraints or color figure charges

- Immediate publication on acceptance

- Inclusion in PubMed, CAS, Scopus and Google Scholar

- Research which is freely available for redistribution 